\title{
Collective academic supervision: a model for participation and learning in higher education
}

\author{
Helle Merete Nordentoft • Rie Thomsen • Gitte Wichmann-Hansen
}

(C) Springer Science+Business Media B.V. 2012

\begin{abstract}
Supervision of graduate students is a core activity in higher education. Previous research on graduate supervision focuses on individual and relational aspects of the supervisory relationship rather than collective, pedagogical and methodological aspects of the supervision process. In presenting a collective model we have developed for academic supervision of Danish master students, we seek to fill these gaps. The underlying pedagogical rationale for the model is that students' participation and learning are interconnected. The model provides possibilities for incorporating a progressive and systematic interaction between master students in their individual writing processes. In the article, we investigate the potentials and challenges of the model and draw on analyses of six individual interviews with master students and one focus group interview with five supervisors. Our findings show that students learn core academic competencies in collective academic supervision (CAS), such as the ability to assess theoretical and practical problems in their practice and present them to peers. The analysis reveals that interaction between divergent projects and voices in CAS can be highly productive in academic learning. However, the model also challenges both students and supervisors because both parties are used to a oneto-one supervisory relationship and not prepared for different modes of participation and learning. According to both supervisors and students, the majority of supervisors need better training in the facilitation of collective supervision processes.
\end{abstract}

H. M. Nordentoft $(\bowtie) \cdot$ R. Thomsen $\cdot$ G. Wichmann-Hansen Faculty of Arts, Aarhus University, Paludan Müllers Vej 48, 8200 Aarhus N, Denmark e-mail: hnj@dpu.dk

R. Thomsen e-mail: riet@dpu.dk

G. Wichmann-Hansen

e-mail: cfugwh@hum.au.dk 
Keywords Graduate supervision - Collective - Academic Higher education · Participation · Learning

\section{Introduction}

In an academic environment, learning is often an individual rather than a group undertaking and students' isolation is, moreover, a frequent problem (Simons 2005). In spite of this challenge a quick glance at the oft-cited handbooks for supervisors illustrates a striking lack of focus on collective or collaborative forms of supervision (Delamont et al. 2004; Taylor and Beasley 2005; Eley and Jennings 2005; Eley and Murray 2009; Walker and Thomson 2010). When issues of collaboration are addressed in research on supervision, they are frequently considered in a secondary and indirect manner as a discipline-specific characteristic of research cultures and doctoral supervision practice within the sciences as opposed to the humanities (Egan et al. 2009; Heath 2002; Wright and Cochrane 2000; Neumann 2003). We have developed a collective model for master students' academic supervision to reduce their isolation and as a measure "to ensure that students experience a congenial culture and develop networks with their peers" (Simons 2005, p. 11). Moreover, we argue that the model potentially increases and qualifies students' participation and academic learning by stimulating their motivation to study and to write academic assignments. The model is called "Collective Academic Supervision" (CAS). In this article we present a case study of how we have developed CAS at the Faculty of Arts, Aarhus University, and of the ways in which supervisors and students have responded to the model. We use the term academic about the supervision process because the students in CAS engage in

The most important craft of academic work, the productive process of giving and accepting critique. Not only does this result in better products, they also learn the procedures and standards of the academic community (Lillejord and Dysthe 2008, p. 83).

Collective academic supervision provides a framework for the supervision and offers students systematic, progressive, and academic input from peers and supervisors which encourage their writing process. Another pivotal incentive behind the model for collective supervision is the expectation that it can inspire and support academic staff in their work to supervise more than one student at a time. Furthermore, if supervisors use the same model for collective academic supervision, common reference points can be created, both theoretically and methodologically, from which supervision at universities can be evaluated, criticised and developed.

In the first part of this article, we describe the theoretical and methodological foundations of CAS. We then present the CAS model followed by a discussion of the resulting challenges in terms of students' participation and academic learning. The basis for this discussion is an analysis of six interviews conducted individually with master students and one focus group interview involving five supervisors. Finally, we outline implications for future research into collective supervision methods in higher education.

\section{Supervision in higher education}

The notion of learning through peers and groups has been thoroughly discussed, applied, and investigated in courses, programs, and other formal classroom contexts within the 
general field of teaching and learning in higher education. Still, there has been little theorization of this practice and little documentation of its application in supervision contexts (Boud and Lee 2005). An emerging strand in recent research however, explores community or collective approaches to both graduate and postgraduate supervision (Simons 2005; Parker 2009; Boud and Lee 2005). Within this strand, authors generally refer to a learning community approach (Parker 2009) and argue that collective supervision fora provide students with possibilities for participation that differ from one-to-one supervision (Thomsen 2012). In a group, students can participate not only as speakers and listeners, but also as observers of a conversation between peers or a fellow student and the supervisor (Vehvilâinen 2009, p. 186). This perspective on learning is founded on a situated perspective (Lave and Wenger 1991) where learning is understood as a phenomenon which is constituted in interaction and rooted in the learner's participation in and adaptation to social practices (Carlgren 2009; Marsh-Piirainen and Tainio 2009). The organization of of social activities frames the participation and, therefore, the learning. Participants, on the other hand, also change and modify the structures through their participation (Dreier 1999; Lave 2008). A situated perspective on learning and participation emphasises the importance of context-not as "an entity someone is put into" (Martin 2009). Instead context is understood in a reflexive sense inspired by ethnomethodology and conversation analysis in which "the participants build the context of their talk in and through their talk" (Heritage 1997, p. 224). In this theoretical tradition reflexivity refers to "what actors' know about' or' make of' and' do in' a setting is also itself constitutive of the setting and informed by it" (Pollner and Emerson 2001, p. 121). In other words context is and is created at the same time. When, for instance, a student raises her hand in class, she orients to her role as a student in a learning context. And by raising her hand she, moreover, constitutes this learning context.

This situated perspective on learning has motivated and guided most of the studies on collective group supervision. These studies all report positive findings with regard to students' learning and the fostering of collaborative cultures in spite of the fact that they focus on a variety of themes. Caffarella and Barnett (2000) and Lee and Boud (2003) both showed how the concept of community of practice can be effectively applied to scholarly writing groups with 8-10 members. Fisher (2006) reported on the advantages of peer support groups defined as "a small group of three to five candidates who meet regularly to discuss content and process of their research projects". Malfroy (2005) undertook an ethnographic study of collaborative knowledge sharing arrangements such as seminars showing that they are evident forums for students to 'learn and watch how to be' academic. In accordance with this study, Manathunga and Goozee (2007) described the role of collective learning groups as a fruitful way to develop independent scholars amongst students. Stracke (2010) concludes in a recent study that a more collaborative research culture is fostered when peer group meetings are combined with traditional supervisory meetings with individual doctoral students.

A development project at the master's program in education at the University of Bergen has tried to deal with the counterproductive and affective aspects of graduate educationsuch as lack of self-confidence, isolation and lack of motivation-in a collective forum (Lillejord and Dysthe 2008). In our development of CAS, we have been especially inspired by Lillejord's and Dysthe's research and the ways in which students' individual activities and learning can be combined with participation and collaborative learning in the academic community. They have, for instance, formed student colloquia and supervision groups consisting of two or three supervisors and their students. Lillejord and Dysthe conclude that differences between the students' projects have been very rewarding for students' 
Table 1 The premises of collective academic supervision

- Students' written material is the cornerstone in CAS. In this material, students present their project and formulate their questions to the supervisor and their peers.

- Students are asked to send their written material and questions to both supervisor and peers in the supervision group before a CAS session.

- All students in the group are expected to read the material before the supervision session.

- The last part of the session is reserved for a discussion of common themes in the students' projects.

- All supervisors at the module meet at least twice during the supervision process: one meeting before and one after CAS begins. The purpose of these meetings is to exchange experiences, introduce new supervisors, and evaluate the process.

academic learning. Conflicts and disagreements were welcomed, not as threats but as productive elements in the learning process. In this process supervisors' ability to facilitate the supervision sessions and students' participation were closely interconnected. Importantly, Lillejord and Dysthe found that supervisors should not rely on students' own initiatives but should "guide and structure their activity in order to enhance participation" (Lillejord and Dysthe 2008, p. 82). In the following, we describe how we have worked with and built upon these findings in the development of CAS.

\section{The model collective academic supervision}

A recent (2011) survey of students' experiences at Aarhus University in Denmark (AU) shows that an alarming number of students feel isolated and adrift. The survey concludes that this problem must be addressed if $\mathrm{AU}$ is to reduce dropout rates and to improve the university's ability to attract international students in a globalized world (AU 2011). In CAS students get an opportunity to receive feedback in a social forum-both orally and in writing. There are normally four or five different student projects in the group, and, therefore, a dynamic interchange between different theoretical/empirical perspectives. The term academic implies a particular approach to knowledge and to the production of knowledge. Namely, that the production of knowledge is systematic, critical, and takes place in a dialogue with a scientific community. Our ambition is to integrate these academic qualities in CAS where students meet, present and give feedback to each other together with their supervisor. In other words, students learn the academic craft by actively engaging in it. In CAS, the differences between the projects should stimulate specific argumentations and theoretical positions. Table 1 describes the premises of Collective Academic Supervision. Tables 2 and 3 illustrate the activities in each module ${ }^{1}$ in the Master Programme in Guidance and Counseling at Aarhus University.

A majority of the master students work as guidance practitioners or counselors during their part time study at the master programme. This shift between work-life and study-life makes a transparent, systematic and progressive structure of the supervision prominent to assist the students in keeping a relevant academic focus in their writing process. The progression of the supervision sessions is structured in a way which supports the thematic progression of the students' projects as described in Table 2.

The Academic Writing Centre is a centre offering writing courses to students from the different master modules, as well as individual writing support and coaching. Students can

\footnotetext{
${ }_{1}$ A module is the same as a semester.
} 
Table 2 Activities in collective academic supervision within the basic modules (modules 1-3)

Product: Written assignment 15 pages

Oral examination: $30 \mathrm{~min}$

Supervision: $8.5 \mathrm{~h}$ per student including examination

and supervisor's preparation of Collective Academic Supervision sessions

\begin{tabular}{ll}
\hline $\begin{array}{l}\text { Supervision seminars } \\
\begin{array}{l}\text { 1. Research Question } \\
\text { seminar }\end{array}\end{array}$ & Activities \\
$\begin{array}{l}\text { 2. Midway seminar } \\
\text { Students are expected to email the following to supervisor and peers: } \\
\text { (a) outline of the project; (b) theoretical and methodological } \\
\text { considerations and questions. }\end{array}$ \\
$\begin{array}{l}\text { Students are expected to email the following to supervisor and peers: (a) examples } \\
\text { of and questions arising from their analysis, and (b) points and questions } \\
\text { expected to feature in the assignment's discussion and conclusion. Students } \\
\text { may send a draft for the entire assignment if they specify which paragraphs } \\
\text { they want feedback on and why. }\end{array}$ \\
\hline
\end{tabular}

consult the centre on their own or be referred by supervisors. Table 3 shows how CAS integrates activities with the courses offered by the Academic Writing Centre during the final module in which students write their master's thesis. During this writing process, a Work in Progress seminar $\left(\mathrm{WIP}^{2}\right)$ is also arranged where students receive feedback not only from their supervisor and peers, but also from another supervisor-as described in Table 3 .

Contrary to Lillejord and Dysthe (2008), we only offer collective supervision in the written introduction to CAS because we believe that it takes a firm structure to instigate CAS. Most students are used to individual supervision and we expect that they would choose individual supervision if they were given the choice. However, we have limited time and resources available for supervision. In addition, the structure of CAS, in which the same supervisor meets with the same group of students, makes it possible for both parties to experience a progression in their work, both personally and professionally. This progression may create a feeling of community, in turn stimulating meaningful participation (Bartley et al. 2010).

Collective academic supervision has been running for three years at the Master Programme in Guidance and Counseling. 22 groups from three different modules have participated in the project. We have evaluated the progression of CAS after each module and developed the model on the basis of observations of supervision sessions, students' written evaluations, and interviews with both students and supervisors. Later, in the findings section, we present supervisors' and students' responses to CAS and discuss future research perspectives. Firstly, however, we take a closer look at the method and analytical strategy applied.

\section{Method}

The findings presented later in this article draw on our notes and observations from 22 supervisory groups, six individual qualitative interviews with master students from six different supervision groups, and one focus group interview with five supervisors. The

\footnotetext{
2 The concept of work in progress seminars is inspired by a similar concept developed by the Doctoral School of Organisational Learning (DOCSOL) at DPU, Aarhus University.
} 
Table 3 Activities in collective academic supervision, within the thesis module (module 4)

Product: Written assignment 50 pages including own empirical study

Oral examination: $45 \mathrm{~min}$

Supervision: $24 \mathrm{~h}$ including examination and supervisor's preparation of Collective Academic Supervision sessions

Supervision seminars Activities

1. Getting started

Exchanging ideas and plans for the projects. The goal is to develop a work plan for the project. In this session we discuss:

- Choice of topic and motivation

- Drafts for research questions

- Drafts of the project design. Which theories and methodologies are possible?

- Time schedule for the writing process

- Introduction to the supervision process and to coaching in pairs

Workshop in the academic writing centre

2. Half-way response At this session we discuss: table of contents plus selected paragraphs from the projects (theory/analysis). Requests for response must be presented as questions related to the written material.

Workshop in the academic writing centre

3. Work in progress (WIP)
At a WIP seminar you get the opportunity to:

- Present your project: What are the goals of your project? Why-and how do you intend to pursue these goals - theoretically and empirically?

- Receive focused response from peers and another supervisor than your own. The response from peers and supervisors is a good preparation for questions and topics which may arise at the oral examination. Students who have not sent in written material prior to the WIP seminar are welcome to attend the seminar but don't receive feedback. They are, however, encouraged to sit in and listen to the discussion. Students participating in the seminar present two questions which opponents should respond to when reading the student's material.

Structure of the WIP seminar:

Each project is allocated 30 minutes. The time is divided as follows:

- The student has five minutes to briefly introduce the questions he/she raises in the written material-i.e. why do I ask the questions I ask?

- The student acting as opponent has seven minutes to comment on these questions. The simple ground rule for constructive response should be remembered: praise — critique-praise. The opponent is also asked to evaluate the clarity of the student's communication and argumentation. What is being investigated and how? Which discussions does the project raise? Finally, the opponent is asked to formulate three questions which the student should consider in his/her future work.

- Next, an opponent/supervisor has seven minutes to give his/her feedback. - Ten minutes are then set aside for discussion. Here, other students at the seminar can ask questions and comment on the project.

- Finally, the student is asked what his/her next steps are in the writing process-i.e. how does he/she plan to incorporate the feedback provided at the seminar.

The opponents are not to be interrupted during their presentation of comments and questions. The student listens and takes notes. After the response he/she can ask questions and comment on the issues the oppo-nents have brought up. Here it is a good idea to avoid long explanations. Instead it is better to ask the opponents to elaborate on their comments and on how the challenges which have been raised might be tackled. 
interviews were conducted with students and supervisors from the same module, module 3 , at the master's programme in guidance at Aarhus University during the autumn of 2011. The students have been exposed to CAS for three consecutive modules. In the interviews, they draw on their overall experiences with CAS and not only with module 3 . We have used the same interview guide with open-ended questions (Kvale 1996) in all the interviews. These questions invite the informants to tell about their previous and present experiences with collective supervision and, specifically, what they consider to be the potentials and limitations of CAS. To ensure validity and prevent personal and professional conflicts of interest, the interviews were conducted, transcribed verbatim and analysed by someone other than the student's supervisor.

\section{Analysis}

The interviews with students and supervisors were coded and a content analysis was performed in which the transcripts were grouped into categories to identify common and emerging themes related to the challenges and possibilities CAS presents for student learning in the master's programme (Kvale 1996). Analytical rigor was ensured via triangulation of the different perspectives (i.e. from the different individual interviews), and multiple data sources (observations from the supervisory sessions, individual and focus group interviews).

\section{Findings and discussion: potentials and challenges in collective academic supervision}

We now turn our attention to an analysis and discussion of how CAS works, what it can offer, and its limitations. This discussion concludes with an outline of possible future perspectives for research into CAS.

We identified four themes in our analysis

Product versus process The challenge of creating a synergy between product and process and between oral and written discussions in CAS. Are student interactions prioritized at the expense of ensuring academic standards?

The supervisory relationship The discussion about balancing professional and private aspects in a collective environment. Is it possible and advisable to be close in the relationship between students and supervisors?

Tuning in This theme reveals how students in CAS support each other in understanding and decoding different supervisory styles, e.g. how would the supervisor like the assignment?

More structure-more participation? This theme addresses the pedagogical competences required of supervisors in CAS. Does CAS call for supervisors with special competences in terms of facilitating groups?

\section{Product versus process}

Most of our informants have welcomed CAS. Students appreciate that the dates for supervision sessions are planned beforehand. Generally, they assess the structure and progression in CAS positively and express that they would never have started the writing 
process 'so early' were it not for CAS. All the students we interviewed stated that they consider it academically rewarding to meet with and get feedback and new ideas from peers. Several students, however, say that they find it difficult to spend energy and time doing more than they are used to, i.e., give feedback to peers, because they also have to take care of their normal day-to-day work as guidance practitioners. This may be why several students do not meet the written requirements of CAS, i.e., hand in written material prior to CAS as described in Tables 1 and 2.

The supervisors all keep returning to the challenge of creating a synergy between product and process, oral and written discussions in CAS. The supervisors state that they find it difficult to balance a focus on a rewarding supervision 'process' with the outcomethe written assignment or 'product' - of the supervision. They question how the supervisor can plan and facilitate CAS and leave room for a combination of symmetrical student-tostudent interaction and more asymmetrical interaction in which the supervisor becomes an expert who comments on the students' papers. Consequently, the challenge the supervisors formulate is twofold: (1) How can it be ensured that students' assignments meet academic standards? (2) How can a collective supervision process facilitate this goal? The dilemma of product versus process is a well-established concept within the research literature on supervision (Kandiko and Kinchin 2012; Chris 2005). In this respect, our informants are no different from traditional supervisors, but the dilemma seems to be particularly highlighted in CAS. For instance, a lack of preparation among students hinders a constructive collective supervision process. Generally, students produce written papers (too) late in the process in spite of the supervisors' encouragement to start early. This lack of preparation frustrates the supervisors, as well as several of the students we spoke to. According to one student, this situation had a negative impact on the working climate in her group and made the group conversations more asymmetrical and less fruitful. As a result, the supervisor was compelled to dominate the sessions more and leave less room for peer feedback.

\section{The supervisory relationship}

When the informants-both supervisors and students-compare collective versus individual supervision, they keep returning to the quality of the supervisory relationship in individual supervision. Two of the five supervisors, for instance, worry that they do not get 'the close professional contact' with the students in CAS, a contact they consider to be better in one-to-one supervision. The three other supervisors in the focus group interview disagree on this point and the interviews with students, moreover, indicate that the majority do not miss individual supervision as much as we had expected. On the contrary, one informant says that she feels more exposed and scrutinized in one-to-one supervision than she does in CAS. In one-to-one-supervision she has experienced that it is her problem-not the supervisor's - if she does not understand what the supervisor says. Another informant states that she sees the supervision process as a personal as well as a professional process and comments that her supervisor's enthusiasm for her project has been crucial for her motivation and writing process. Moreover, she says, that this personal attention was not at the expense of the other students in the group who also received the supervisor's attention and understanding.

Our analysis draws attention to a classical and inherent tension in supervision: Namely the management of personal and professional boundaries in the supervisory relationship. The question is how the supervisor can offer personal support to the student and act as a gatekeeper of the discipline at the same time? (Hermansson 1997; Manathunga 2009). The interviews we have conducted reveal that some students need emotional support as well as 
professional guidance if they are to fully participate in and benefit from CAS. These students potentially become vulnerable and less motivated in CAS because they may be or feel overruled by stronger students (Nordentoft and Kappel 2011). The question is how far a supervisor should go to meet students' needs? Some students may dominate and others may lack confidence when offering and receiving feedback. Some groups may end up operating as what Sapon-Shevin and Chandler-Olcott (2001) label a 'dysfunctional family' due to very different levels of experience and knowledge. A future study could explore different expressions of student vulnerability and how they are dealt with by supervisors and peers within CAS in more depth. Our findings make it relevant to discuss which students benefit from CAS in their writing process and under which circumstances CAS increases participation.

To summarize, the supervisor role is different in CAS than in one-to-one-supervision. In CAS, supervisors' ability to approach students and their projects in a manner which can guide and facilitate relevant and supportive discussions in the group seems an essential skill for supervisors. Moreover, students must be capable of comprehending and acting with the supervisor's facilitation in order to benefit from CAS. Collective academic supervision, therefore, places complex interactional demands on both supervisors and students.

Tuning in: What are the supervisor's expectations for the assignment?

Our analyses reveal that supervisors and students seem to spend a lot of time and energy on getting in tune with one another in CAS in the supervision process. According to one student, supervision is mostly about finding out what the supervisor expects of you. She says:

Well it is about fulfilling those expectations and 'what are those expectations?' and how does this supervisor we are facing interpret the rules we have to live up to? And it is always exciting - or how should I put it—when we come to the supervision [session], that we do not really know...now it is exciting how this supervisor wants it.

This quotation illustrates a general finding. Students experience that different supervisors have different perspectives on what is required in an academic assignment. One student says that, by listening to supervisors when they supervise other students in the group, she learns what this particular supervisor 'wants'-i.e., considers important in the written assignment. The students also talk about different ways in which they help each other in the supervision room and in the writing process. One student uses the term 'witness' to describe how the students support each other. She explains how it is often difficult for her to listen and hear what the supervisor says to her while taking notes at the same time. To solve this problem she has begun to ask her peers to listen and to write down what they hear the supervisor saying. "In this way, one might say we become each others witnesses", she states. Moreover, these discussions in CAS often make the students more inclined to meet after CAS and continue their conversation, and to clarify their understandings of, for instance, theoretical concepts which have been introduced in CAS. One student tells how the CAS group met at a café after the exam to discuss the results and their feelings about it.

In conclusion, the analysis of the interviews with students shows that CAS creates opportunities for students to support each other, both professionally and personally, and both inside and outside the supervisory room, during their studies. The students appear to 
appreciate the opportunity for peer support in dealing with the insecurity and academic demands the writing process entails instead of being left to their own devices. In this respect, our analysis of the student interviews indicates that supervisors differ considerably in terms of their supervisory styles and make very different demands on students. This reflects a core issue often addressed in the general literature on one-to-one supervision (Taylor and Beasley 2005). This literature points out that it is crucial for all parties in the supervision process to have a mutual and clear understanding of institutional requirements for supervision, including course objectives and assessment criteria. Institutions merely define the formal framework. The lived supervision practice depends on how supervisors and students interpret and implement this framework (McPhail and Erwee 2000). Consequently, a number of authors suggest that it is vital that supervisors spend time right from the start discussing and negotiating the rules, roles, and responsibilities of all parties (Wisker G 2001; Grant and Graham 1994; Eley and Murray 2009). According to the literature and our empirical data this recommendation seems to be crucial, especially for supervision in collective forums. Below, we elaborate further on this point by arguing that general challenges, familiar from one-to-one supervision, become more specific and even magnified in CAS.

More structure: more participation?

The supervisor's facilitation is important, but the basic structure in CAS still gives students the possibility to alternate between speaking and listening to other students and their reflections. The modes of participation are expanded and the students get an opportunity to "formulate and say things out loud" according to one of the informants. Peers may ask questions like "What does this mean? And: why is this concept relevant here?" One informant specifically asserts that students do not have this opportunity in one-to-one supervision or in lectures. However, analysis of the data reveals that supervision does not necessarily become collective or even academic just because the CAS model is introduced. One student states that it is not enough to send out written introductions about the structure of CAS beforehand - these instructions need to be followed up by more specific instructions about the ways in which the students can work together in the group. For instance, several students assert that the supervisor needs to take a more structured approach when facilitating supervision, rather than just letting the students exchange feedback with no specific guidelines about methods for giving and receiving feedback. Otherwise the students who shout the loudest get the most supervision and/or speaking time. According to the informants, this unfortunately seems to reflect a more general tendency in several of the groups. "We are not competent to guide one another...I sometimes feel that we are exchanging our common ignorance when we talk", as one student puts it. In many cases, the lack of facilitation means that the students receiving supervision first get more supervision time than those who come last. One student explains how this lack of facilitation can be very stressful.

I do not think it is my place to say to the other students: Now we have to stop because we have to move on-it is the supervisor's job.... So I have been sad several times after the supervision and I had this feeling. I was embarrassed because I did not have anything against my peers but there is not a lot of time when we are four students in the group.

So, rightfully, this student does not think that it is her place to intervene and take over the control of the session. Evidently, she is frustrated because the session does not move on. 
Another informant, meanwhile, comments that the facilitation in her group was too strict. Her group had been working together for two previous modules and the group members, therefore, knew each other fairly well and had developed their own way to discuss projects in the group. The supervisor intervened too much and was too focused on the final assignment in the facilitation.

In summary, the analysis of interviews with the students and supervisors demonstrates that there is a (too) big difference between the ways in which CAS is conducted. This appears to be confusing and at times stressful for both parties in that they constantly have to negotiate and adjust the structure of the supervision and their roles and relationships.

\section{Future perspectives}

The supervisors have found CAS inspiring to work with but wish to learn more about the ways in which they can facilitate CAS and include different pedagogical activities. Some supervisors find CAS challenging and time consuming, because they experience that students request individual supervision after CAS. Our analysis suggests that students request this supervision because supervisors do not, as mentioned previously, have competences to supervise in a collective forum and satisfy the needs of all students in the group. Still, further investigation is needed to comprehend the implications of CAS for students' learning in higher education. What is the relationship between supervisors' practice of CAS and students' participation and learning? Which structures lead to more participation? Does the structure of CAS benefit strong supervisors and students and leave the less academic/experienced behind? Rienecker and Hermansen (Rienecker and Hermansen 2007) write about the need for supervisors to meet in a collegial forum and discuss professional, didactic and personal aspects of supervision. In this regard, the systematic meetings between the supervisors before and after CAS are evaluated positively by participants. This study is explorative and further research including more data may explore all of the above challenges in more detail. As we write this article, we have just finished another developmental project in which we have worked with such a collegial forum. A collegial approach to educational development is strongly recommended in recent studies on academic development in general and studies on supervisor development (Brew, 2010; Blass et al., 2012; Emilsson and Johnsson, 2007). In our project, five supervisors have met regularly over 6 months and shared and discussed video observations of CAS in order to develop their competences to supervise collectively. In a forthcoming article, we detail and discuss this project.

\section{Conclusion}

In this article we have investigated 'how collective supervision works' and what it 'works to do' by highlighting pedagogical and methodological aspects of the supervision process in a case study at the Master Programme of Guidance and Counselling at Aarhus University in Denmark. Specifically, we have explored the potentials and challenges offered by a model for collective supervision called "Collective Academic Supervision" in which students who work with each their individual assignment come together, discuss, and exchange feedback in a systematic and progressive way. The development of CAS is rooted in a socio-cultural perspective on learning in which participation and learning are interconnected. A change in participation provides for a change in learning. Moreover, the structure of a social activity like CAS frames the possibilities for participation and 
systematic interaction among students when they are writing their individual academic projects and, therefore, potentially increases their learning. Our study indicates that master's students learn academic competencies in CAS, such as the capability to assess core theoretical and practical problems orally and in writing and, moreover, present them to peers. As Lillejord and Dysthe (2008) propose in their work, the interviews reveal that diversity and divergent voices are productive in academic learning. However, this productivity requires that supervisors become better qualified and learn to improve their facilitation of CAS. At its best, students learn science by practicing science in CAS-i.e., academic questioning, response and critique with peers and supervisors as co-participants in the academic community. When the master students return to their practices as guidance practitioners and counselors we, moreover, believe that his learning potentially improves their communication and collaboration with clients and professionals from different practice fields than their own.

\section{References}

AU. (2011). Studiemiljøundersøgelsen [Survey of students' experiences at Aarhus University]. Aarhus.

Bartley, K., Dimenäs, J., \& Hallnäs, H. (2010). Student participation in higher education. Nordic Studies in Education, 30, 150-165.

Blass, E., Jasman, A., \& Levy, R. (2012). Supervisor reflections on developing doctoralness in practicebased doctoral students. Quality Assurance in Education, 20(1), 31-41.

Boud, D., \& Lee, A. (2005). 'Peer learning' as pedagogic discourse for research education. Studies in Higher Education, 30(5), 501-516.

Brew, A. (2010). Transforming academic practice through scholarship. International Journal for Academic Development, 15(2), 105-116.

Caffarella, R., \& Barnett, B. (2000). Teaching doctoral students to become scholarly writers: The importance of giving and receiving critiques. Studies in Higher Education, 25(1), 39-51.

Carlgren, I. (2009). Commentary: Ca-studies of learning-From an educational perspective. Scandinavian Journal of Educational Research, 53(2), 203-209. doi:10.1080/00313830902757618.

Chris, P. (2005). New variant PhD: The changing nature of the doctorate in the UK. Journal of Higher Education Policy and Management, 27(2), 189-207.

Delamont, S., Atkonson, P., \& Parry, O. (2004). Supervising the Doctorate: A guide to success (2nd ed.). NY: Open University Press.

Dreier, O. (1999). Personal trajectories of participation across contexts of social practice. Outlines, 1999(1), 5-32.

Egan, R., Stockley, D., Brouwer, B., Tripp, D., \& Stechyson, N. (2009). Relationsships between area of academic concentration, supervisory style, student needs and best practices. Studies in Higher Education, 34(3), 337-345.

Eley, A. R., \& Jennings, R. (2005). Effective Postgraduate Supervision: Improving the Student/Supervisor Relationship. NY: Open University Press.

Eley, A., \& Murray, R. (2009). How to be an Effective Supervisor: Best practice in research student supervision. NY: Open University Press.

Emilsson, U. M., \& Johnsson, E. (2007). Supervision of supervisors: On developing supervision in postgraduate education. Higher Education Research \& Development, 26(2), 163-179.

Fisher, K. (2006). Peer support groups. In C. Denholm \& T. Evans (Eds.), Doctorates downunder: Keys to successful doctoral study in Australia and New Zealand (pp. 41-49). Camberwell, Victoria: Acer Press.

Grant, B., \& Graham, A. (1994). Guidelines for discussion: a tool for managing postgraduate supervision. In: O. Zuber-Skerritt \& Y. Ryan (Eds.), Quality in Postgraduate Education. London: Kogan Page.

Heath, T. (2002). A quantitative analysis of PhD students' views of supervision. Higher Education Research \& Development, $21(1), 41-53$.

Heritage, J. (1997). Conversation analysis and institutional talk. In D. Silverman (Ed.), Qualitative research: Theory, method and practice (pp. 222-245). London: Sage.

Hermansson, G. (1997). Boundaries and boundary management in counselling: The never-ending story. British Journal of Guidcance and Counselling, 25(2), 133-145. 
Kandiko, C. B., \& Kinchin, I. M. (2012). What is a doctorate? A concept-mapped analysis of process versus product in the supervision of lab-based PhDs. Educational Research, 54(1), 3-16.

Kvale, S. (1996). Interviews-An introduction to qualitative research interviewing. Thousand Oaks: CA Sage.

Lave, J. (2008). Epilogue: Situated learning and changing practice. In A. Amin \& J. Roberts (Eds.), Community, Economic, Creativity, and Organization. Oxford and New York: Oxford University Press.

Lave, J., \& Wenger, E. (1991). Situated learning, legitimate peripheral participation. New York: Cambridge University Press.

Lee, A., \& Boud, D. (2003). Writing groups, change and academic identity: Research development as local practice. Studies in Higher Education, 28(2), 187-200.

Lillejord, S., \& Dysthe, O. (2008). Productive learning spaces-a theoretical discussion based on two cases. Journal of Education and Work, 21(1), 75-89. doi:10.1080/13639080801957154.

Malfroy, J. (2005). Doctoral supervision, workplace research and the changing pedagogic practices. Higher Education Research and Development, 24(2), 165-178.

Manathunga, C. (2009). Supervision as a contested space: a response. Teaching in Higher EducatioTeaching in Higher Education, 14(3), 341-345.

Manathunga, C., \& Goozee, J. (2007). Challenging the dual assumption of the 'always/already' autonomous student and effective supervisor. Teaching in Higher Education, 12(3), 309-322.

Marsh-Piirainen, A., \& Tainio, L. (2009). Collaborative game-play as a site for participation and situated learning of a second language. Scandinavian Journal of Educational Research, 53(2), 167-183. doi: $10.1080 / 00313830902757584$.

Martin, C. (2009). Relevance of situational context in studying learning as changing participation. Scandinavian Journal of Educational Research, 53(2), 133-149. doi:10.1080/00313830902757568.

McPhail, J., \& Erwee, R. (2000). Developing professional relationships between supervisors and doctoral candidates. Australian Journal of Management and Organisational Behaviour, 3(1), 76-99.

Neumann, R. (2003). The doctoral education experience: Diversity and complexity. Canberra: Australian Department of Education Science and Training.

Nordentoft, H. M., \& Kappel, N. (2011). Vulnerable participants in health research. Methodological and ethical challenges. Journal of Social Work Practice, 25(3), 365-376. http://dx.doi.org/10.1080/ 02650533.2011 .597188 .

Parker, R. (2009). A learning community approach to doctoral education in the social sciences. Teaching in Higher Education, 14(1), 43-54.

Pollner, M., \& Emerson, R. M. (2001). Ethnomethodology and ethnography. In P. Atkinson, A. Coffey, S. Delamont, J. Lofland, \& L. Lofland (Eds.), Handbook of ethnography (pp. 118-135). London: Sage Publications.

Rienecker, L., \& Hermansen, M. (2007). Udvikling af vejledning fra tavs viden og privatpraktiserende kultur til italesættelse of institutionalisering. Dansk Universitetspaedagogisk Tidsskrift, 3, 1-4.

Sapon-Shevin, M., \& Chandler-Olcott, K. (2001). Communities of critique or dysfunctional families? Journal of Teacher Education, 52(5), 350-364.

Simons, P. (2005). An issue of isolation. In A. R. Eley \& R. Jennings (Eds.), Effective postgraduate supervision: Improving the student-supervisor relationship (pp. 7-12). Maidenhead United Kingdom: Open University Press.

Stracke, E. (2010). Undertaking the journey together: Peer learning for a successful and enjoyable PhD experience. Journal of University Teaching \& Learning Practice, 7(1). Article 8.

Taylor, S., \& Beasley, N. (2005). A Handbook for Doctoral Supervisors. London: Routledge.

Thomsen, R. (2012). Career Guidance in Communities. Aarhus: Aarhus University Press. (in press).

Vehvilâinen, S. (2009). Problems in the research problem: Critical feedback and resistance in academic supervision. Scandinavian Journal of Educational Research, 53(2), 185-201. doi:10.1080/003138 30902757592.

Walker, M., \& Thomson, P. (Eds.) (2010). The Routledge Doctoral Supervisor's Companion: Supporting effective research in Education and the Social Sciences. London: Routledge.

Wright, T., \& Cochrane, R. (2000). Factors influencing successful submission of PhD theses. Studies in Higher Education, 25(2), 181-195. 